\title{
The mechanism of mitochondrial membrane potential retention following release of cytochrome $c$ in apoptotic GT1-7 neural cells
}

\author{
AC Rego ${ }^{1,2}$, S Vesce ${ }^{1}$ and DG Nicholls*,1 \\ ${ }^{1}$ Buck Institute for Age Research, Novato, CA 94945, USA \\ 2 Current address: Laboratory of Biochemistry, Faculty of Medicine and Center \\ for Neurosciences of Coimbra, University of Coimbra, 3004-504 Coimbra, \\ Portugal \\ * Corresponding author: DG Nicholls, Buck Institute for Age Research, Novato, \\ CA 94945, USA. Tel: +1 415209 2095; Fax: +1 415209 2232; \\ E-mail: dnicholls@buckinstitute.org
}

Received 11.4.01; revised 18.5.01; accepted 29.5.01

Edited by $\mathrm{G}$ Kroemer

\begin{abstract}
The relationship is investigated between mitochondrial membrane potential $\left(\Delta \Psi_{\mathrm{M}}\right)$, respiration and cytochrome $c$ (cyt c) release in single neural bcl-2 transfected cells (GT17bcl-2) or GT1-7puro cells during apoptosis induced by staurosporine (STS). Bcl-2 inhibited the mitochondrial release of cyt $c$ and apoptosis. Three different cell responses to STS were identified in GT1-7puro cells: (i) neither $\Delta \Psi_{M}$ nor cyt $c$ were significantly affected; (ii) a decrease in $\Delta \Psi_{M}$ was accompanied by a complete release of cyt $c$; or (iii) cyt $c$ release occurred independently of a loss of $\Delta \Psi_{\mathrm{M}}$. The endogenous inner membrane proton leak of the in situ mitochondria, monitored by respiration in the presence of oligomycin, was increased by STS by $92 \%$ in puro cells, but by only $23 \%$ in bcl-2 cells. STS decreased respiratory capacity, in the presence of protonophore, by $31 \%$ in purocells and by $20 \%$ in bcl-2 cells. In the absence of STS, oligomycin hyperpolarized mitochondria within both puro and bcl-2-transfected cells, indicating that the organelles were net generators of ATP. However after $15 \mathrm{~h}$ exposure to STS oligomycin rapidly collapsed residual mitochondrial polarization in the puro cells, indicating that $\Delta \Psi_{M}$ had been maintained by ATP synthase reversal. bcl-2 cells in contrast, maintained $\Delta \Psi_{\mathrm{M}}$ until protonophore was added. These results indicate that the maintenance of $\Delta \Psi_{\mathrm{M}}$ following release of cyt $c$ may be a consequence of ATP synthase reversal and cytoplasmic ATP hydrolysis in STS-treated GT1-7 cells. Cell Death and Differentiation (2001) 8, 995-1003.
\end{abstract}

Keywords: apoptosis; cytochrome $c$; GT1-7 cells; mitochondrial membrane potential; staurosporine

Abbreviations: FCCP, carbonylcyanide- $p$-(trifluoromethoxy) phenylhydrazone; STS, staurosporine; $\Delta \Psi_{\mathrm{M}}$, mitochondrial membrane potential; $\mathrm{TMRM}^{+}$, tetramethylrhodamine methyl ester; PS, phosphatidylserine; cyt $c$, cytochrome $c$

\section{Introduction}

In recent years, mitochondria have become centrally implicated in the process of apoptotic cell death. ${ }^{1,2}$ Release of mitochondrial cytochrome $c$ (cyt $c$ ) is promoted by the proapoptotic proteins Bax and Bak, whereas anti-apoptotic members of this family prevent the release of the cytochrome. $^{3}$ The mechanisms responsible for cyt $c$ release are controversial; both non-specific rupture of the outer membrane, as a consequence of matrix swelling induced by the mitochondrial permeability transition, and activation of a specific outer membrane channel, perhaps involving the outer membrane porin, have been proposed. ${ }^{4}$ While it is unreasonable to expect that a single global mechanism will account for all observations, a key discriminator has been the mitochondrial membrane potential, $\Delta \Psi_{\mathrm{M}}$, during the apoptotic process, since a permeability transition would be associated with a collapse in potential, while activation of a specific outer membrane channel need not involve any bioenergetic disruption. Unfortunately, a number of studies have used inappropriate methodologies to monitor $\Delta \Psi_{\mathrm{M}}{ }^{5}$ and the central question concerning the bioenergetic competence of the mitochondria to generate ATP has generally not been addressed.

Exposure to the non-selective protein kinase inhibitor staurosporine (STS) induces apoptosis in a variety of cells; ${ }^{6-10}$ however the mechanism is still largely unknown. Heiskanen et al. ${ }^{8}$ reported that STS-induced apoptosis in PC6 cells was associated with a synchronous release of cyt $c$ (as a green-fluorescent-protein construct) and collapse of $\Delta \Psi_{\mathrm{M}}$. However other investigators have found that the release of cyt $c$ into the cytosol during STSinduced apoptosis occurs independently of mitochondrial depolarization. $^{9-11}$

The cell death repressor protein $\mathrm{Bcl}-2$ inhibits cellular free radical formation ${ }^{12-14}$ and cyt $c$ release, ${ }^{15}$ blocks the activation of caspases $^{16}$ and inhibits apoptosis. ${ }^{17} \mathrm{Bcl}-2$ increases the capacity of mitochondria to accumulate $\mathrm{Ca}^{2+18}$ and shifts the redox potential of cells towards reduction. ${ }^{19}$ Vander Heiden et al. $^{6}$ have reported that $\mathrm{Bcl}-$ $x(L)$-expressing cells adapt to STS treatment by maintaining a decreased $\Delta \Psi_{\mathrm{M}}$, while Shimizu et al. ${ }^{20}$ have suggested that $\mathrm{Bcl}-2$ over-expression decreases the effectiveness of protonophores in depolarizing the mitochondria by enhancing ion flux.

Mitochondrial membrane potential can be controlled by proton leakage across the inner membrane, ATP synthesis (or hydrolysis), substrate availability, electron flux through the respiratory chain and ion transport. In order to establish which, if any, of these factors influence $\Delta \Psi_{M}$ during STS exposure we have investigated changes in $\Delta \Psi_{M}$ and cyt $c$ retention in single neural GT1-7 cells transfected with a 
recombinant retrovirus carrying $b c /-2$ and a puromycin resistance gene (GT1-7bcl-2) or a control construct (GT17puro) during apoptosis induced by STS. We suggest that some of the ambiguity in the literature may stem from the ability of mitochondria that have released cyt $c$ to maintain a high $\Delta \Psi_{\mathrm{M}}$ by ATP synthase reversal.

\section{Results}

\section{Bcl-2 expression, STS-mediated apoptosis and cyt $c$ release}

STS-induced apoptosis of GT1-7 cells is accompanied by caspase activation, nuclear fragmentation and DNA laddering. ${ }^{16}$ Figure 1 shows that the cells display other characteristic changes including externalisation of phosphatidylserine (PS) (Figure 1A) and loss of cyt $c$-like immuno-activity from mitochondria (Figure 1C) and cells (Figure 1B). GT1-7puro cells do not express detectable amounts of Bcl-2 (Figure 1C), but expression of the protein in the GT12-7bcl-2 cells (Figure 1C) confers protection against STS-induced apoptosis, preventing PS externalization (Figure 1A), nuclear condensation and cell death (Figure 1A) and cyt $c$ depletion from mitochondria (Figure 1C) and cells (Figure 1B).

\section{Mitochondrial membrane potential and cyt $c$ retention}

Changes in in situ mitochondrial membrane potential can be monitored by confocal microscopy using fluorescent cationic probes loaded at low concentrations insufficient to induce aggregation and fluorescence quenching within the matrix. Tetramethylrhodamine methyl ester $\left(\mathrm{TMRM}^{+}\right)$loaded at $10 \mathrm{nM}$ into a field of GT1-7puro cells that had been exposed to $500 \mathrm{nM}$ STS for $15 \mathrm{~h}$ revealed a heterogeneous response, with many cells retaining $\mathrm{TMRM}^{+}$indicating a population of polarized mitochondria (Figure 2B). Mitochondria within GT12-7bcl-2 cells similarly exposed to STS were uniformly polarized (data not shown). Since Figure 1 showed extensive cyt $c$ depletion in STS-exposed puro cells it was important to establish the relationship between $\Delta \Psi_{\mathrm{M}}$ and cyt $c$ retention in individual cells. This was accomplished by fixing and immunostaining the same field of cells whose mitochondrial membrane potential had been monitored. Figure $2 \mathrm{C}$ shows that only a sub-population of cells displaying $\mathrm{TMRM}^{+}$ fluorescence were immuno-reactive for cyt $c$ (see for example cells arrowed 'c'). Thus mitochondria can lose their cyt $c$ during apoptosis by a mechanism independent of a collapsed $\Delta \Psi_{\mathrm{M}}$. Figure $2 \mathrm{D}-\mathrm{F}$ shows a group of four cells enlarged from Figure $2 \mathrm{~A}-\mathrm{C}$. All four cells maintain $\mathrm{TMRM}^{+}$ fluorescence, but cell 'b' contains no detectable cyt $c$ immunoactivity.

Since electron transfer between mitochondrial complexes III and IV is catalysed by cyt $c$ the question is raised as to how $\Delta \Psi_{M}$ is maintained in cells whose mitochondria have released the cytochrome. In the absence of electron transport the only mechanism for generating and maintaining $\Delta \Psi_{M}$ is reversal of the ATP synthase utilizing cytoplasmic ATP derived from glycolysis. The ATP synthase inhibitor oligomycin has proved a useful tool to investigate ATP synthase directionally in cultured neurons undergoing excitotoxic degeneration. ${ }^{21,22}$ Briefly, by blocking proton re-entry through an ATP synthase engaged in net ATP synthesis, oligomycin will hyperpolarize the mitochondria. Alternatively, mitochondria with inhibited respiration or a moderately proton-leaky inner membrane can still maintain a $\Delta \Psi_{M}$ by ATP synthase reversal, in which case oligomycin will rapidly depolarize the mitochondria.

Assessing the functional ability of in situ mitochondria to generate ATP is of more value than a simple qualitative estimate of mitochondrial polarization, since it defines the functionality of the organelles. The oligomycin 'null-point' assay can be used under two different loading conditions. If the loading is sufficient for aggregation of the probe in the matrix and consequent fluorescence quenching, then mitochondrial hyperpolarization will be reflected in a decreased whole-cell fluorescence as cytoplasmic probe is accumulated into the quenching environment of the matrix. ${ }^{21}$ Conversely depolarization will cause an elevation of signal as probe is released back into the cytoplasm before re-equilibrating across the plasma membrane. These effects are demonstrated in Figure 3 for GT17 puro and GT1-7bcl-2 cells. Figure $3 \mathrm{~A}, \mathrm{~B}$ show that oligomycin causes similar hyperpolarizing effects on puro and $b c / 2$ cells. Thus both cells with control and bcl-2 constructs maintain a sufficiently high membrane potential for net ATP synthesis. No difference in the rate of probe redistribution was detected following addition of the protonophore FCCP. Thus we cannot substantiate claims that $\mathrm{Bcl}-2$ expression inhibits protonophore-induced changes in $\Delta \Psi_{\mathrm{M} \cdot}{ }^{20,23}$

In order to model the change in whole-cell fluorescence which would occur upon oligomycin addition if $\Delta \Psi_{M}$ were being maintained by ATP synthase reversal, puro and $b c /-2$ cells were treated with rotenone, which causes maximally about $90 \%$ inhibition of complex I. Such respiratory chain inhibition induces ATP synthase reversal, which limits the extent of mitochondrial depolarization. Thus Figure 3C,D show the very slight mitochondrial dequenching observed under these conditions in, respectively, puro and bcl-2 cells. The further addition of oligomycin now causes depolarization and hence further dequenching (Figure 3C,D). Antimycin A, which totally inhibits complex III causes further depolarization and the decay of $\Delta \Psi_{\mathrm{M}}$ is accelerated by the protonophore FCCP.

We were unable to obtain convincing evidence of oligomycin-induced mitochondrial depolarization within STS-treated puro cells using the above aggregationdependent assay in which mitochondrial depolarization should generate a transient increase in whole-cell fluorescence (data not shown). Experiments were therefore repeated at confocal resolution with GT1-7 cell equilibrated with $10 \mathrm{nM} \mathrm{TMRM}{ }^{+}$, a low, non-quenching concentration (Figure 4). Figure 4A shows a representative pair of control puro cells. Mitochondrial fluorescence is retained for at least $15 \mathrm{~min}$ in the presence of oligomycin but is rapidly dissipated by FCCP. Figure $5 \mathrm{~A}$ shows the time-course of the integrated whole cell fluorescence from representative non-exposed puro cells in response to oligomycin and 
A

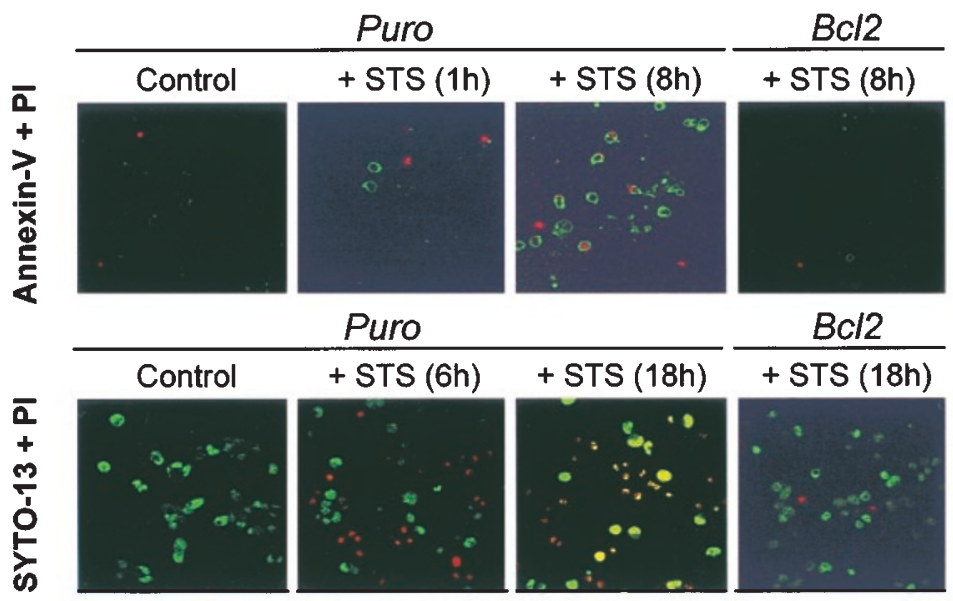

B

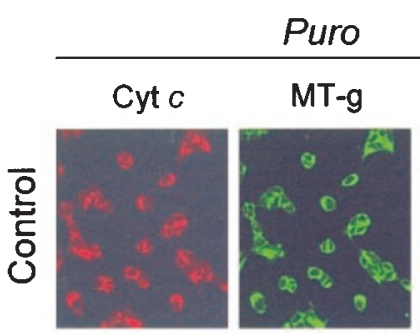

Cyt c + MT-g

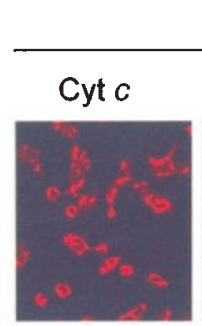

$\mathrm{Bc} / 2$
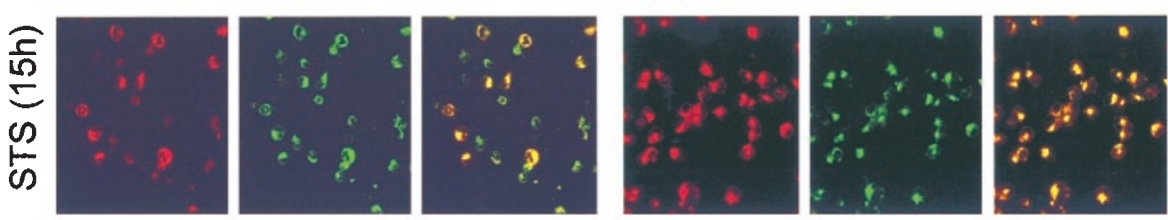

C

$\begin{array}{llll}1 & 2 & 3 & 4\end{array}$

Anti-Bcl2

Anti-Cyt c

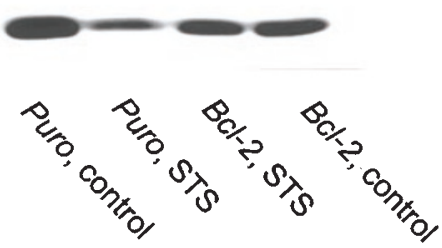

Figure 1 STS-induced apoptosis and mitochondrial cyt $c$ release in GT1-7 cells - effect of Bcl-2. (A) The cells (GT1-7puro and GT1-7bcl-2) were incubated with $0.5 \mu \mathrm{M}$ STS for the indicated period and imaged for phosphatidylserine exposure by labeling with Annexin V plus propidium iodide (PI) or for chromatin condensation with SYTO-13 (green) plus PI (red). Co-localization of SYTO-13 plus PI indicates necrotic or late apoptotic cells. Images are representative from 3-4 independent experiments. (B) Control cells or cells exposed to $0.5 \mu \mathrm{M} \mathrm{STS} \mathrm{for} 15 \mathrm{~h}$ were co-labeled with anti-cyt $c$ antibody and MitoTracker-green (MT-g). Overlay of fluorescence indicates retention of mitochondrial cyt $c$ in bcl-2 cells treated with STS. (C) Immunoblots of cytoplasmic Bcl-2 expression and mitochondrial cyt $c$ in control cells and cells exposed to $0.5 \mu \mathrm{M}$ STS for $15 \mathrm{~h}$

FCCP. The slight increase in fluorescence under these non-quenching conditions reflects a mitochondrial hyperpolarization as probe accumulates into the mitochondrion and the cytoplasm restores the Nernst equilibrium across the plasma membrane. ${ }^{21}$ The histograms show the mean responses from three independent experiments.
Figure 4B shows three representative puro cells after $15 \mathrm{~h}$ exposure to STS. Note that only one of the cells retains mitochondrial $\mathrm{TMRM}^{+}$. Upon addition of oligomycin the mitochondrial fluorescence starts to decay and is almost undetectable after $15 \mathrm{~min}$, indicating that $\Delta \Psi_{\mathrm{M}}$ was being previously maintained by ATP synthase reversal 
TMRM $^{+}$
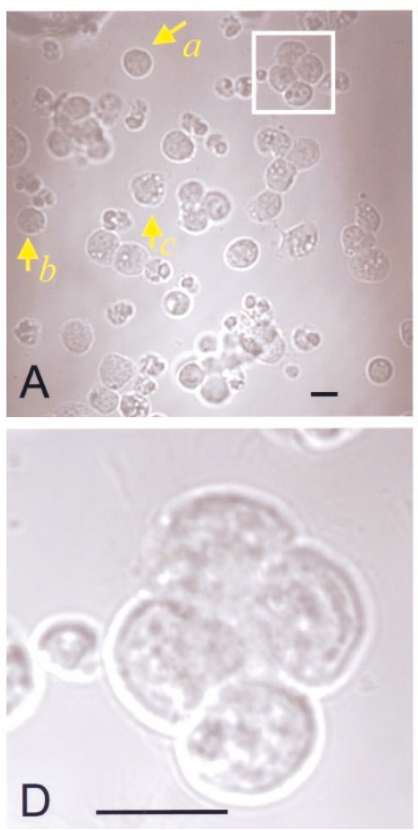
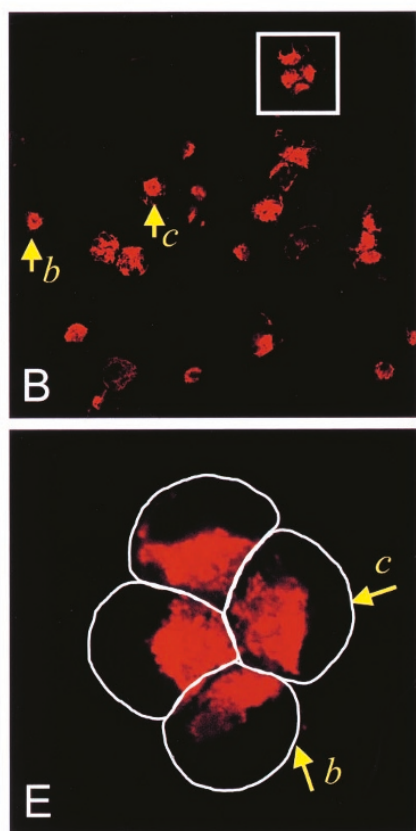

Cyt $c$
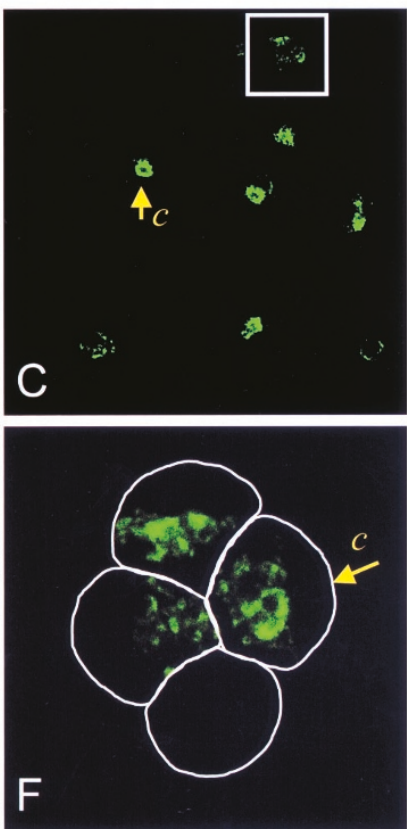

Figure $2 \mathrm{TMRM}^{+}$fluorescence and cyt $c$ immunoactivity in puro cells treated with STS. Cells preincubated with $0.5 \mu \mathrm{M} \mathrm{STS}$ for $12 \mathrm{~h}$ were equilibrated with $10 \mathrm{nM}$ for $30 \mathrm{~min}$, imaged for TMRM ${ }^{+}$fluorescence, fixed without disturbing the field and labeled with monoclonal cyt $c$ antibody and secondary antibody conjugated with FITC. (A) bright-field image; (B) TMRM ${ }^{+}$fluorescence; (C) cyt $c$ staining of the same field. Note the presence of three distinct responses to STS: a, a cell that shows complete mitochondrial depolarization and is not labeled for cyt $c$; b, a cell that retains $\Delta \Psi_{\mathrm{M}}$ even though cyt $c$ has been released; .c, a cell that retains both $\Delta \Psi_{\mathrm{M}}$ and cyt $c$. (D-F) enlargement of the insert. The bar represents $10 \mu \mathrm{m}$. Results are representative of five independent experiments

A

\section{GT1-7puro cells}

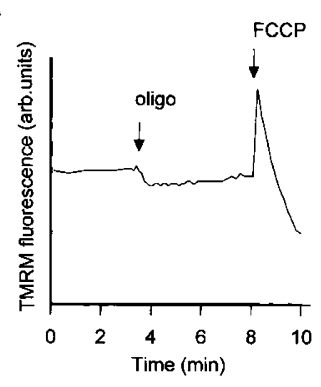

C

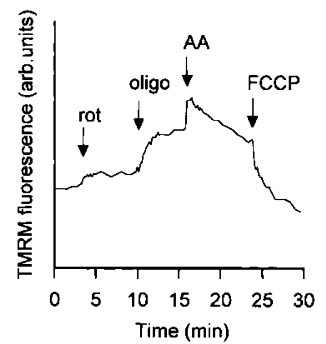

B

GT1-7bc/2 cells

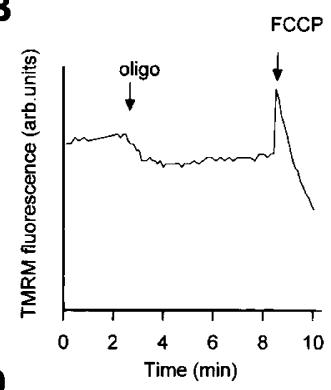

D

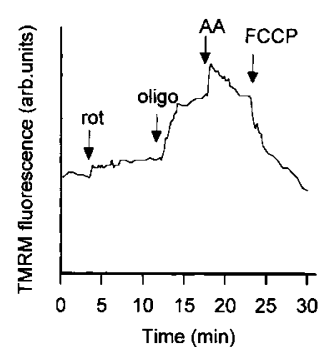

Figure 3 Oligomycin-induced changes in $\Delta \Psi_{M}$ in puro and $b c l-2$ cells: effect of respiratory chain inhibition. GT1-7puro or GT1-7bcl-2 cells were loaded with $50 \mathrm{nM} \mathrm{TMRM}^{+}$. Where indicated, $5 \mu \mathrm{g} / \mathrm{ml}$ oligomycin (oligo) $2.5 \mu \mathrm{M} \mathrm{FCCP,} 2 \mu \mathrm{M}$ rotenone (rot) or $2 \mu \mathrm{M}$ antimycin A (AA) were added. Each trace is from a single cell soma representative of at least 15 cells from three independent experiments utilizing cytoplasmic ATP. This oligomycin-induced depolarisation is apparent in the time-course and mean results (Figure 5B). Analysis of fluorescence was performed only with the sub-set of cells retaining $\mathrm{TMRM}^{+}$fluorescence after treatment with STS.

The mitochondria of the STS-exposed bcl-2-cells as a whole retain the ability to generate ATP and hyperpolarize on addition of oligomycin (Figure 5D). Interestingly, a minority of cells still depolarize following addition of the inhibitor, thus Figure 4D shows a pair of cells one of which retains potential and one of which shows a decay of potential after oligomycin.

\section{Cell respiration}

To further investigate the mean bioenergetic state of the mitochondrial population in STS-exposed cells, respiration of intact cells was determined (Table 1). In the absence of STS the rates of oxygen consumption in control GT1-7puro cells were not statistically different from those in GT1-7bcl-2 cells. However, the endogenous inner membrane proton leak of the in situ mitochondria, monitored by respiration in the presence of oligomycin, was increased by STS by $92 \%$ in puro cells, but by only $23 \%$ in $b c /-2$ cells.

Furthermore, oligomycin failed significantly to inhibit respiration in these cells, which could indicate that the mitochondria were failing to generate ATP or that substrate supply and/or electron transport were limiting respiration. The latter is confirmed by the marginal stimulation of respiration 
A) puro -STS
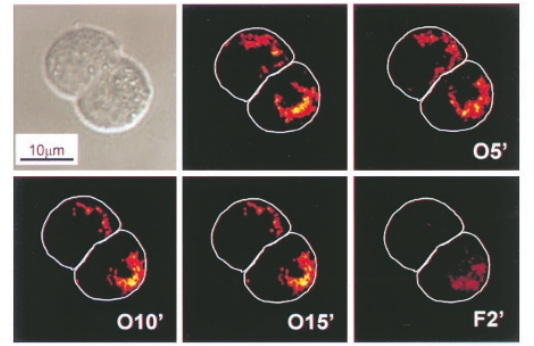

C) $B c / 2$-STS
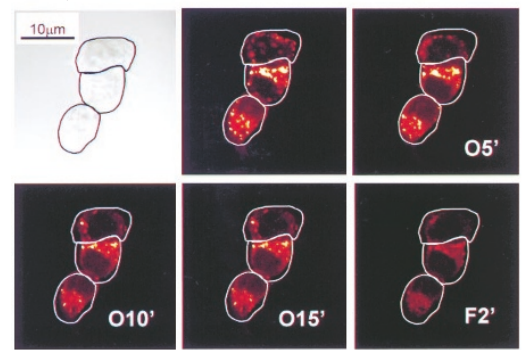

B) puro + STS

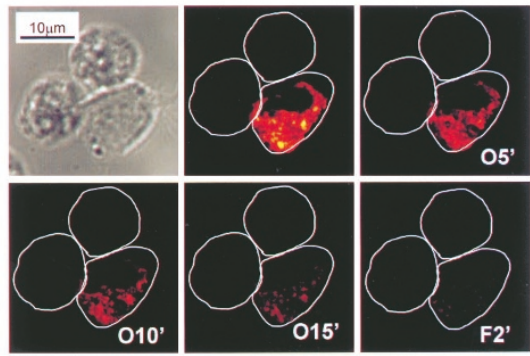

D) $\mathrm{Bcl} 2+\mathrm{STS}$

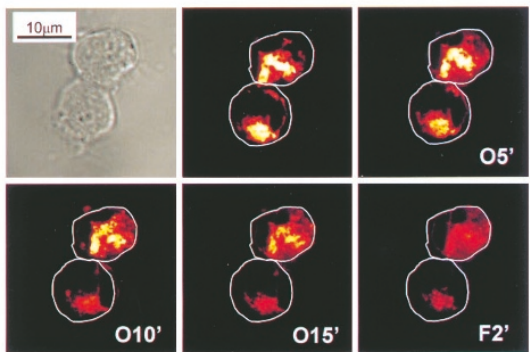

Figure 4 Oligomycin depolarizes STS-treated puro but not $b c l-2$ cells. GT1-7puro or bcl-2 cells were incubated in the absence or presence of $0.5 \mu \mathrm{M}$ STS for $15 \mathrm{~h}$. Cells were then loaded with $10 \mathrm{nM} \mathrm{TMRM}^{+}$for $30 \mathrm{~min}$, washed and analyzed by confocal microscopy in the presence of TMRM ${ }^{+}$. Fluorescence was monitored before and after exposure of cells to $5 \mu \mathrm{g} / \mathrm{ml}$ oligomycin for $5\left(\mathrm{O5}^{\prime}\right), 10\left(\mathrm{O} 10^{\prime}\right)$ or $15\left(\mathrm{O}^{\prime} 5^{\prime}\right)$ min, and 2 min after addition of $2.5 \mu \mathrm{M}$ FCCP (F2'). Note the mitochondrial depolarization upon addition of oligomycin in STS-treated puro cell that retained $\mathrm{TMRM}^{+}$. Images are representative from at least five independent experiments
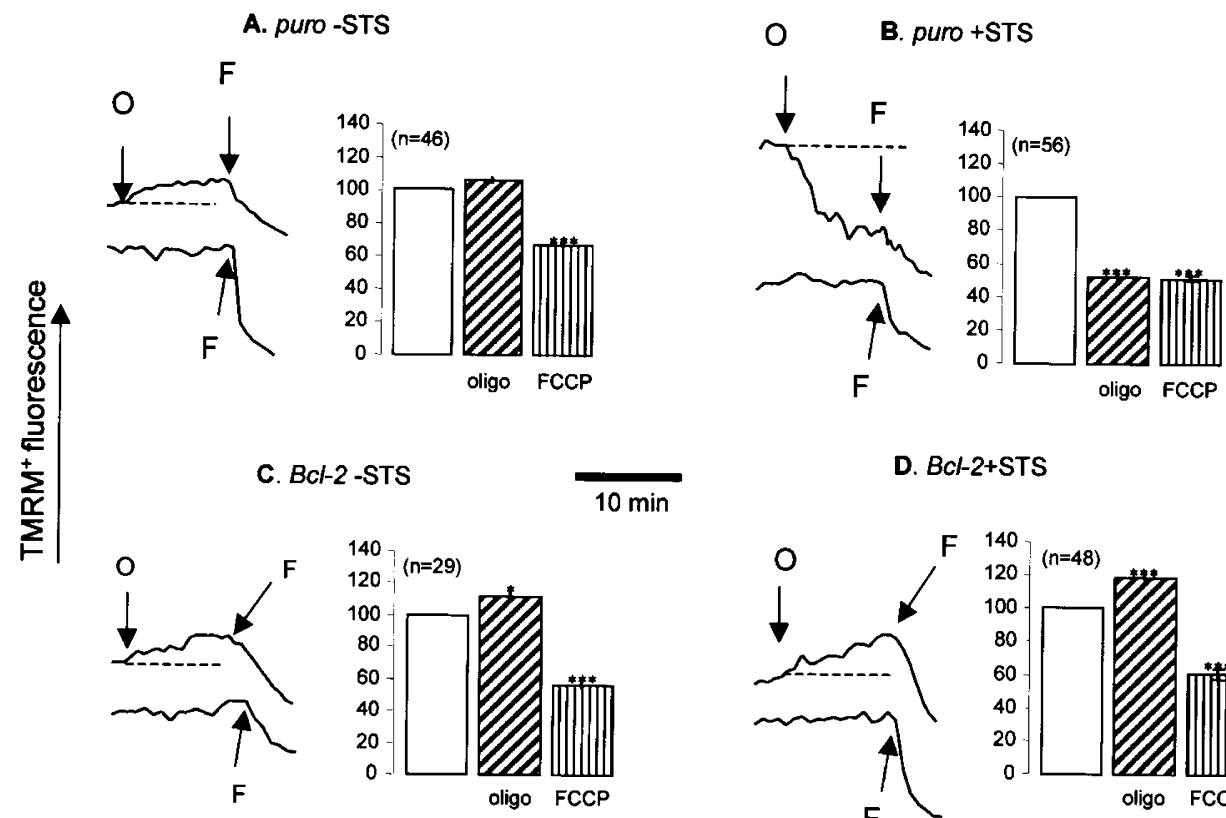

D. Bcl-2+STS

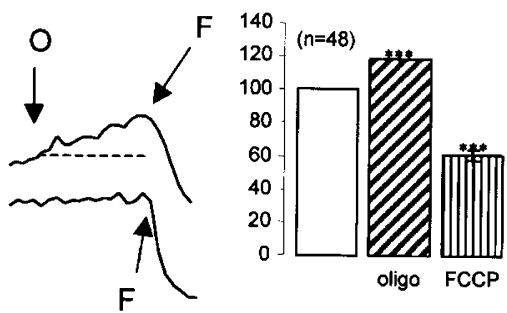

Figure 5 Oligomycin depolarizes STS-treated puro but not $b c l-2$ cells. GT1-7puro or bcl-2 cells were incubated in the absence or presence of $0.5 \mu \mathrm{M}$ STS for $15 \mathrm{~h}$, equilibrated with $10 \mathrm{nM} \mathrm{TMRM}^{+}$and exposed to oligomycin (O) and/or FCCP (F) as described in Figure 4 legend. Single-cell fluorescence intensity was monitored in the confocal microscope. The histograms represent the means and S.E.M. of 29-56 cells from at least three independent experiments

on addition of protonophore to STS-treated puro cells (Table 1) and the observation that STS decreased respiratory capacity, in the presence of protonophore, by $31 \%$ in puro cells and by $20 \%$ in $b c /-2$ cells. The lack of respiratory control of the mitochondria in the puro cells is a further indication of a sub-optimal $\Delta \Psi_{M}$ in the mitochondrial population. 
Table 1 Oxygen consumption of GTI-7 cells: effect of staurosporine exposure

\begin{tabular}{|c|c|c|c|}
\hline & Endogenous rate & +Oligomycin & +FCCP \\
\hline & \multicolumn{3}{|c|}{ (nmol O/min/mg cell protein) } \\
\hline $\begin{array}{l}\text { Puro, control } \\
\text { Puro+STS, } 15 \mathrm{~h} \\
\text { Bcl-2, control } \\
\text { Bcl-2+STS, } 15 \mathrm{~h}\end{array}$ & $\begin{array}{l}33.1 \pm 3.4 \\
15.8 \pm 2.9^{*} \\
28.1 \pm 1.3 \\
20.8 \pm 1.0\end{array}$ & $\begin{array}{c}7.7 \pm 0.6 t \\
14.7 \pm 1.3^{\star *} \\
7.1 \pm 0.6 t t t \\
8.7 \pm 0.5 t t t\end{array}$ & $\begin{array}{l}26.8 \pm 1.9 t \\
18.6 \pm 0.8^{\star} \\
19.1 \pm 0.6 t+t \\
15.4 \pm 1.3^{*} t\end{array}$ \\
\hline
\end{tabular}

The rates of endogenous (state 3) plus oligomycin (state 4) or plus FCCP (uncoupled) oxygen consumption were determined in intact puro or bcl-2-transfected GT1-7 cells upon trypsinization, as described in Materials and Methods. The respiration of apoptotic cells was measured in cells treated with $0.5 \mu \mathrm{M}$ staurosporine (STS), for $15 \mathrm{~h}$. Control cells were incubated for the same time without STS. The rates of oxygen consumption are expressed as mmol oxygen per minute per mg protein. The data are the means \pm S.E.M. of four experiments. Statistical significance: ${ }^{\star} P<0.05$ as compared to the puro control; $\$ P<0.05, \$ \uparrow P<0.01$ or $\$+\$ P<0.001$ of state 4 data as compared to state 3 , or uncoupled data as compared to state 4 , for each experimental condition

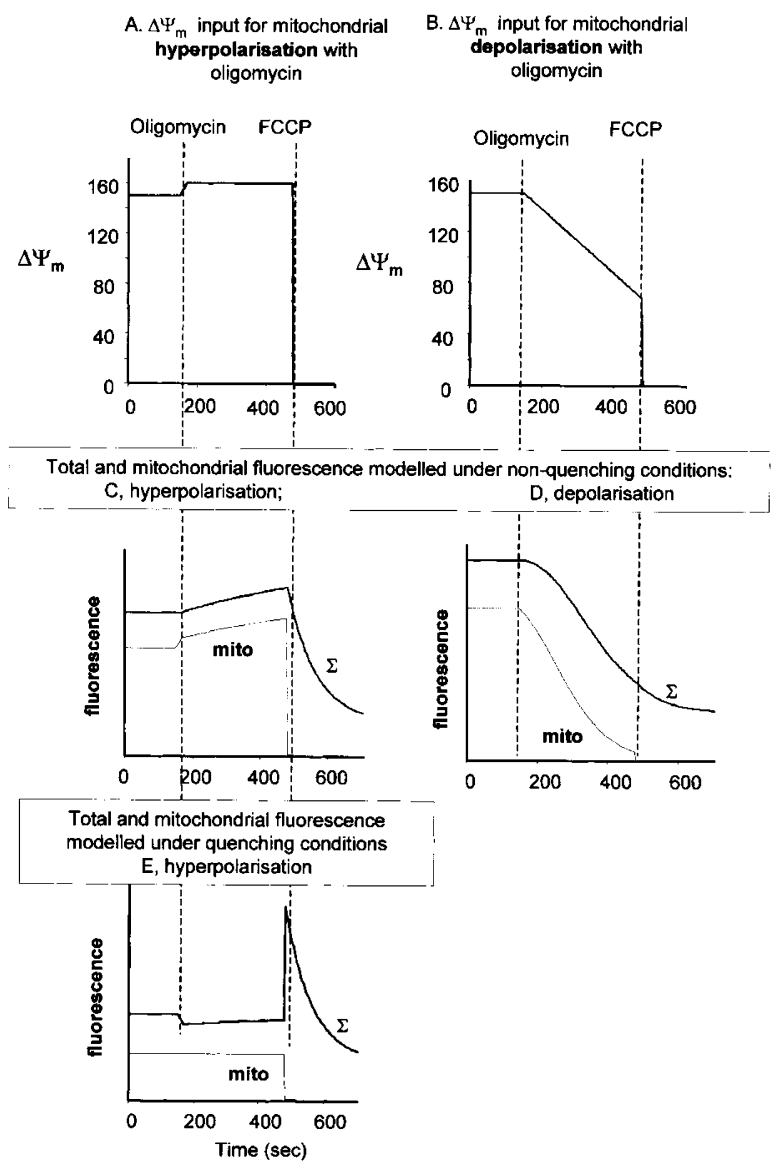

Figure 6 Simulation of single-cell and in situ mitochondrial fluorescence in response to changes in mitochondrial membrane potential associated with oligomycin addition. The simulation is detailed in ${ }^{23}$ and is available on-line at http://www.buckinstitute.org/nicholls.htm. The following parameters were employed: plasma membrane potential, $-60 \mathrm{mV}$ (constant); starting $\Delta \Psi_{\mathrm{M}}$ $-150 \mathrm{mV}$; matrix volume relative to cytoplasm, $1 \%$; plasma membrane rate constant, $0.02 \mathrm{~s}^{-1}$; $\mathrm{TMRM}^{+}$concentration $10 \mathrm{nM}(\mathbf{C}, \mathbf{D})$ or $50 \mathrm{nM}(\mathbf{E})$; matrix quench threshold $60 \mu \mathrm{M}$. Addition of oligomycin 'hyperpolarized' cells by $10 \mathrm{mV}$ or caused a linear depolarization of $1 \mathrm{mV} / \mathrm{min}$. Compare trace $\mathbf{C}$ with Figure $5 \mathrm{~A}, \mathrm{C}$ or $\mathrm{D}$; compare trace $\mathbf{D}$ with Figure $5 \mathrm{~B}$ and compare trace $\mathbf{E}$ with Figure $3 A, B$

\section{Discussion}

Much of the prolonged controversy on the relationship between the time-course of mitochondrial polarization, cyt $c$ release and apoptosis has stemmed from the inappropriate use of cationic membrane-permeant fluorescent dyes to monitor $\Delta \Psi_{\mathrm{M}}$. As demonstrated in Figure 6C,E, diametrically opposite responses are obtained if the dyes are loaded into cells at concentrations sufficient to exceed matrix concentrations at which dye aggregation and fluorescent quenching occurs. ${ }^{5}$ We have previously presented a program in Microsoft Excel that uses simple, verifiable assumptions to model the fluorescence response of single cells equilibrated with potentiometric probes. ${ }^{21}$ These assumptions are that probes are non-selectively permeable across plasma and mitochondrial membranes, that they seek to equilibrate towards a Nernst equilibrium across both membranes, that the half-time for equilibration across the inner mitochondrial membrane is much faster than across the plasma membrane due to the greater surface/volume ratio of the former, and finally that matrix fluorescence is proportional to probe concentration until the threshold for formation of the nonfluorescent dye aggregate is reached.

The response of representative control puro and bcl2 cells to the sequential additions of oligomycin and FCCP under quenching conditions (50 nM TMRM ${ }^{+}$, Figure $3 \mathrm{~A}, \mathrm{~B}$ ) or non-quenching conditions (10 nM $\mathrm{TMRM}^{+}$, Figure $\left.5 \mathrm{~A}, \mathrm{C}\right)$ can be modeled by a $10 \mathrm{mV}$ hyperpolarization upon oligomycin addition and a total collapse of $\Delta \Psi_{\mathrm{M}}$ with FCCP (Figure 6A). The simulation under non-quenching conditions (Figure 6C) closely resembles the experimental traces in Figure 5A,C,D. It should be noted that this simulation is transformed into the corresponding simulated trace for matrix quenching conditions (Figure 6e) merely by increasing the 'extracellular' probe concentration parameter in the simulation from 10 to $50 \mathrm{nM}$. This simulation now closely resembles the experimental traces obtained in the non-confocal single-cell fluorescence traces reported in Figure $3 \mathrm{~A}, \mathrm{~B}$ for puro and $b c /-2$ cells not exposed to STS.

The decrease in fluorescence of the STS-exposed puro cells equilibrated with low $\mathrm{TMRM}^{+}$following oligomycin addition is more difficult to model accurately. However the time course of the decrease, and the insensitivity to subsequent addition of FCCP, can be reproduced by a linear mitochondrial depolarization at $1 \mathrm{mV} / \mathrm{min}$ following oligomycin addition. This solution to the simulation is not intended to be unique, but rather to illustrate the response to an oligomycin-induced decay of a $\Delta \Psi_{\mathrm{M}}$ that had been maintained by ATP hydrolysis.

There is clearly no single mechanism for the release of cyt $c$ from mitochondria. Heiskanen et al. ${ }^{8}$ observed a 
parallel mitochondrial depolarization and release from mitochondria of green-fluorescent-protein conjugated cyt $c$ in STS-treated PC6 cells. However, other reports have shown that cyt $c$ release can occur before major changes in $\Delta \Psi_{\mathrm{M}}$, suggesting that mitochondrial depolarization occurs independently and is not a factor required for the release of cyt $c^{9,11,24}$ The $\mathrm{BH} 3-$ only proteins, such as Bid and Bad, and unlike Bax/Bak, were shown to induce cyt $c$ release without changes in $\Delta \Psi_{\mathrm{M}}$ or the opening of the permeability transition pore and without interacting with VDAC. ${ }^{25}$ In all these studies it is of course essential to confirm that the fluorescence changes are being accurately reported. The loading concentration of probe is particularly important. In the GT1-7 cells, equilibration with $50 \mathrm{nM} \mathrm{TMRM}^{+}$exceeds the quench threshold and results in a decreased whole-cell signal in response to mitochondrial hyperpolarization (see Figures $3 \mathrm{~A}$ and $6 \mathrm{E}$ ) whereas $10 \mathrm{nM}$ probe shows a slow increase in signal under the same conditions (see Figures $5 \mathrm{~A}$ and $6 \mathrm{C}$ ). The appropriate concentration is particularly vital where flow cytometry is employed to monitor potential. As reported by Rottenberg and $\mathrm{Wu}^{26}$ exceeding the quench threshold means that the whole-cell signal becomes insensitive to changes in $\Delta \Psi_{\mathrm{M}}$, and this can be validated in the 'virtual cell' simulation. ${ }^{21}$ The threshold for rhodamine 123 quenching is passed when loading concentrations are in the $\mathrm{nM}$ range; ${ }^{26}$ thus studies such as those of VanderHeiden et al. ${ }^{6}$ which loaded cells with up to $13 \mu \mathrm{M}$ rhodamine 123 prior to flow cytometry can require reinterpretation.

Cyt $c$ release in the absence of mitochondrial depolarization has been ascribed to a transient opening of the permeability transition pore. ${ }^{27}$ Our data suggest that cells can maintain $\Delta \Psi_{\mathrm{M}}$ following cyt $c$ release by ATP hydrolysis. The decrease in state 3 respiration upon incubation with STS (Table 1) may account for the inhibition of electron transport and compromised respiratory function, which may form the basis for the hydrolysis of ATP. A decrease in state 3 respiration may be due to oxidative damage of the inner mitochondrial membrane or the mitochondrial complexes, which inhibits the electron transport and may increase membrane leakiness (producing the enhanced state 4 respiration, Table 1 ). Bcl-2 has been reported to prevent changes in $\Delta \Psi_{\mathrm{M}}$ associated with protonophore-induced apoptosis in $\mathrm{PC} 12$ cells $^{23}$ or to prevent protonophores from depolarizing mitochondria from $\mathrm{Bcl}-2$ expressing cells. ${ }^{20}$ However, our data indicates that FCCP mediates depolarization as effectively in bcl-2 cells as in puro cells (Figure 3 ).

\section{Materials and Methods}

\section{Materials}

GT1-7 cells transfected with a recombinant retrovirus carrying $b c /-2$ and a puromycin resistance gene (GT1-7 bcl-2) and a control construct (GT1-7puro) were kindly donated by Dr. Bredesen (Buck Institute, CA, USA). Tetramethylrhodamine methyl ester $\left(\mathrm{TMRM}^{+}\right)$, fura-2 acetoxymethyl ester (Fura-2/AM), MitoTracker-Green, SYTO-13 and propidium iodide were obtained from Molecular Probes (Leiden,
Netherlands). Annexin V-FITC apoptosis detection kit and STS were from Calbiochem-Novabiochem Ltd. Nottingham, UK). Cyt $c$ antibodies, against native and denatured forms, were obtained from PharMingen (San Diego, CA, USA). Dulbecco's modified Eagle's medium (DMEM), Hank's balanced salt solution (HBSS) and TrypsinEDTA were from Gibco-BRL (Paisley, Strathclyde, UK). Poly-L-lysine $(70-150 \mathrm{kDa})$, fetal bovine serum, penicillin/streptomycin and antiIgG antibodies conjugated with TRITC or FITC were obtained from Sigma Chemical Co. (Poole, Dorset, UK).

\section{Culture of GT1-7 cells (puro and bcl-2 transfected)}

GT1-7 cells, a hypothalamic neuron cell-derived line (GT1-7puro cells) ${ }^{28}$ and $b c l-2$ transfected cells (GT1-7bcl-2 cells), as previously verified by Mah et al. ${ }^{17}$ or Kane et al., ${ }^{29}$ were maintained in DMEM containing $25 \mathrm{mM}$ D-glucose, supplemented with $10 \%$ heat-inactivated fetal bovine serum, $100 \mathrm{U} / \mathrm{ml}$ penicillin and $100 \mu \mathrm{g} / \mathrm{ml}$ streptomycin on poly-L-lysine coated plates, in an atmosphere of $5 \%$ $\mathrm{CO}_{2} / 95 \%$ air, at $37^{\circ} \mathrm{C}$. The medium was changed every 3 days. One day before the experiments, the cells were harvested by trypsinization (0.05\% Trypsin-0.53 mM EDTA in HBSS without $\mathrm{Ca}^{2+}$ and $\mathrm{Mg}^{2+}$ ) and plated at a density of $0.04 \times 10^{6}$ cells $/ \mathrm{cm}^{2}$ in $22 \mathrm{~mm}$ square coverslips for confocal imaging, at a density of $0.08 \times 10^{6} \mathrm{cells} / \mathrm{cm}^{2}$ in $13 \mathrm{~mm}$ round coverslips for epifluorescence imaging, at a density of $0.24 \times 10^{6}$ cells $/ \mathrm{cm}^{2}$ in $60 \mathrm{~mm}$ dishes for intact cell respiration and at a density of $0.7-0.9 \times 10^{6}$ cells $/ \mathrm{cm}^{2}$ in $100 \mathrm{~mm}$ dishes for mitochondrial isolation and Western blotting analysis.

\section{Induction of apoptosis and incubation of GT1-7 cells}

Apoptotic cell death was induced by treating the cells with the protein kinase inhibitor STS (500 nM), in complete DMEM, for 1-18 h. After the treatment, the cells were rapidly and gently washed and incubated with Krebs-Ringer solution (basal medium), containing (in $\mathrm{mM}$ ): 127 $\mathrm{NaCl}, 5.5 \mathrm{KCl}, 2 \mathrm{MgSO}_{4}, 2 \mathrm{CaCl}_{2}, 0.5 \mathrm{KH}_{2} \mathrm{PO}_{4}, 20$ HEPES, 10 glucose, $\mathrm{pH} 7.4$, at $37^{\circ} \mathrm{C}$. Where otherwise indicated, the cells were exposed to $5 \mu \mathrm{g} / \mathrm{ml}$ oligomycin and $2.5 \mu \mathrm{M}$ FCCP.

\section{Immunocytochemistry for detection of cyt $c$ release from the mitochondria}

Cells grown on 22-mm square coverslips were washed in basal medium and incubated with $750 \mathrm{nM}$ MitoTracker-Green (in basal medium) for $60 \mathrm{~min}$, at $37^{\circ} \mathrm{C}$. Cells were then washed with phosphate-buffered saline solution (PBS) and fixed using freshly prepared $3.5 \%$

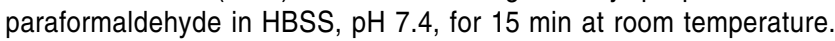
The cultures were washed in PBS, incubated with $20 \mathrm{mM}$ glycine/PBS, for $15 \mathrm{~min}$, and permeabilized with freshly prepared $0.1 \%$ saponin/PBS, for $30 \mathrm{~min}$, at room temperature. The cells were incubated with a purified mouse anti-cyt $c$ monoclonal antibody (PharMingen) that recognizes the native form of cyt $c(1: 100$, diluted in $0.1 \%$ saponin/PBS $)$ for $30 \mathrm{~min}$ at room temperature. The cells were washed and further incubated with a secondary anti-mouse IgG antibody conjugated with TRITC (1:50, diluted in $0.1 \%$ saponin/PBS) for $30 \mathrm{~min}$, at room temperature. Coverslips were prepared with mounting medium for fluorescence on a microscope slide and examined by confocal microscopy.

\section{Single cell epifluorescence imaging}

Mitochondrial membrane potential was monitored with tetramethylrhodamine methyl ester at a loading concentration sufficient to cause dye 
aggregation within the mitochondrial matrix. ${ }^{5}$ For combined $\mathrm{TMRM}^{+}$ and fura-2 imaging, the cells, cultured on round coverslips, were loaded with $30 \mu \mathrm{M}$ fura-2/AM and $50 \mathrm{nM} \mathrm{TMRM}^{+}$for 30 min at $37^{\circ} \mathrm{C}$, in basal medium containing $30 \mu \mathrm{g} / \mathrm{ml}$ bovine serum albumin and $0.003 \%$ pluronic acid. After washing, single cell fluorescence was monitored in the presence of $\mathrm{TMRM}^{+}$by triple-wavelength excitation at 340/380/ $488 \mathrm{~nm}$ with emission at $>510 \mathrm{~nm}$, using a Nikon DIAPHOT-TMD inverted epifluorescence microscope equipped with a $40 \times$ oil immersion objective and Sutter filter wheel. Processing of fluorescence images was performed using a MiraCal Imaging facility (Life Science Resources, Cambridge, UK).

\section{Confocal imaging}

GT1-7 cells cultured on $22 \mathrm{~mm}$ square coverslips were loaded with $10 \mathrm{nM} \mathrm{TMRM}^{+}$, a concentration insufficient for matrix aggregation ${ }^{5}$ for $30 \mathrm{~min}\left(37^{\circ} \mathrm{C}\right)$ and mounted in a Warner RC-21B closed bath chamber on a PH-2 heater platform. The images were collected on a Zeiss LSM510 laser scanning confocal microscope. TMRM ${ }^{+}$fluorescence was monitored in basal medium containing $10 \mathrm{nM} \mathrm{TMRM}^{+}$by excitation at $543 \mathrm{~nm}$ and emission at $>585 \mathrm{~nm}$. Images were collected each $30 \mathrm{~s}$.

In order to visualize cyt $c$ in cells that had been labeled with $\mathrm{TMRM}^{+}$, immunofluorescence was performed on the confocal stage to retain the same field, in a similar way as described above, except that the secondary antibody was FITC-conjugated (anti-mouse IgG, 1:50). Cyt $c$ was detected by excitation at $488 \mathrm{~nm}$ and emission at 505$550 \mathrm{~nm}$. Visualization of both mitochondria and cyt $c$ in mounted coverslips was performed by dual excitation at 488 and $543 \mathrm{~nm}$. Cyt $c$ was visualized at $>585 \mathrm{~nm}$ and MitoTracker-green at 505-530 nm.

Apoptotic nuclei were visualized following incubation with $500 \mathrm{nM}$ SYTO-13 (ex $488 \mathrm{~nm}$, em $505-530 \mathrm{~nm}$ ) and $1 \mu \mathrm{M}$ propidium iodide (ex $543 \mathrm{~nm}$, em $584-615 \mathrm{~nm}$ ) in basal medium for $5 \mathrm{~min}$ at $37^{\circ} \mathrm{C}$.

Externalized phosphatidylserine was monitored (ex $488 \mathrm{~nm}$, em $505-530 \mathrm{~nm}$ ) with An Annexin V-FITC apoptosis detection kit (CalBiochem). Propidium iodide (ex 543, em >585 nm) was used to exclude necrotic or late apoptotic cells.

\section{Intact cell respiration}

Rates of cellular respiration were measured in trypsinized cells, after centrifugation (1000 r.p.m. for $5 \mathrm{~min}$ ) in complete DMEM to inhibit further tryptic activity. Cells $\left(5 \times 10^{6}\right.$ in $\left.1 \mathrm{ml}\right)$ were resuspended in basal medium containing glucose and placed in a thermostatically controlled $\left(37^{\circ} \mathrm{C}\right)$ oxygen electrode chamber (Oxytherm, Hansathec Instruments Ltd., Norfolk, UK). State 4 respiration was measured in the presence of $5 \mu \mathrm{gml}$ oligomycin and uncontrolled respiration following addition of $2.5 \mu \mathrm{M}$ FCCP.

\section{Mitochondrial isolation from GT1-7 cells}

After incubation with STS, cells were rinsed twice with ice-cold phosphate-buffered saline and scraped into $1 \mathrm{ml}$ ice-cold isolationbuffer: $250 \mathrm{mM}$ sucrose, $20 \mathrm{mM}$ HEPES-KOH (pH 7.4), $1 \mathrm{mM} \mathrm{Na}$ EGTA and $1 \mathrm{mM} \mathrm{Na}$-EDTA, with $1 \mathrm{mM}$ dithiothreitol, $1 \mathrm{mM}$ phenylmethylsulfonyl fluoride and 1:100 protease inhibitor cocktail (Sigma), containing 4-(2-aminoethyl)benzenesulfonylfluoride, pepstatin A, trans-epoxysuccinyl-L-leucylamido (4-guanidino) butane (E-64), bestatin, leupeptin and aprotinin, added just before the experiment. Cells were homogenized with 20 strokes of a Dounce homogenizer at $0^{\circ} \mathrm{C}$. Nuclei and intact cells were removed by centrifugation at $500 \times g$ for $12 \mathrm{~min}$, at $4{ }^{\circ} \mathrm{C}$. An aliquot of the resulting supernatant $\left(\mathrm{S}_{1}\right)$ was stored at $-80^{\circ} \mathrm{C}$, whereas the rest was subjected to centrifugation at
$9500 \times \mathrm{g}$ for $10 \mathrm{~min}$ at $4^{\circ} \mathrm{C}$, to pellet the mitochondria. The mitochondrial pellet was washed once with the isolation-buffer and centrifuged at $9500 \times \mathrm{g}$ for $10 \mathrm{~min}$ at $4{ }^{\circ} \mathrm{C}$. The resulting pellet was resuspended in the isolation-buffer and frozen at $-80^{\circ} \mathrm{C}$. The protein concentration in the samples was determined by the BioRad protein assay.

\section{Cyt $c$ and $\mathrm{Bcl}-2$ by Western blotting}

Equivalent amounts of protein from the $S_{1}$-supernatant or from the mitochondrial fractions were resolved on $12 \%$ SDS-PAGE, after denaturation at $100^{\circ} \mathrm{C}$ for $5 \mathrm{~min}$ in buffer containing $100 \mathrm{mM}$ Tris- $\mathrm{HCl}$, $\mathrm{pH}$ 6.8, $200 \mathrm{mM}$ dithiothreitol (DTT), 4\% SDS, 0.2\% bromophenol blue and $20 \%$ glycerol. The proteins were transferred onto nitrocellulose (Immobilon ${ }^{\mathrm{TM}}$-P, Millipore) which were incubated overnight at $0-4^{\circ} \mathrm{C}$ in blocking buffer $(25 \mathrm{mM}$ Tris- $\mathrm{HCl}, \mathrm{pH} 7.6,150 \mathrm{mM} \mathrm{NaCl}$ and $0.05 \%$ Tween-20) containing 5\% BSA. Blots were then incubated with mouse anti-cytochrome $c$ antibody (PharMingen) against the denatured mitochondrial protein (1:1000 dilution in blocking buffer containing $1 \%$ BSA) or with mouse anti-Bcl-2 (Santa Cruz Biotechnology, Santa Cruz, CA, USA) at 1:500 dilution, against the denatured $S_{1}$ supernatant protein. After washing, immunoblots were incubated with horseradish peroxidase-conjugated secondary antibody $(1: 1000$ dilution) and autoradiographed with enhanced chemiluminescence (Amersham Pharmacia Biotech).

\section{Statistical analysis}

Numerical data are presented as means \pm S.E.M. for the indicated number of experiments; for statistical analysis Student's test was used.

\section{References}

1. Li P, Nijhawan D, Budihardjo I, Srinivasula SM, Ahmad M, Alnemri ES and Wang $X$ (1997) Cytochrome $c$ and dATP-dependent formation of Apaf-1/caspase- 9 complex initiates an apoptotic protease cascade. Cell 91: 479-489

2. Jiang $X$ and Wang $X$ (2000) Cytochrome $c$ promotes caspase- 9 activation by inducing nucleotide binding to Apaf-1. J. Biol. Chem. 275: 31199-31203

3. Shimizu S, Narita M and Tsujimoto Y (1999) Bcl-2 family of proteins regulate the release of apoptogenic cytochrome $c$ by the mitochondrial channel VDAC. Nature 399: $483-487$

4. Crompton $M$ (2000) Bax, Bid and the permeabilization of the mitochondrial outer membrane in apoptosis. Curr. Opin. Cell Biol. 12: 414-419

5. Nicholls DG and Ward MW (2000) Mitochondrial membrane potential and cell death: mortality and millivolts. Trends Neurosci. 23: 166-174

6. Vander Heiden MG, Chandel NS, Williamson EK, Schumacker PT and Thompson CB (1997) Bcl- $x_{L}$ regulates the membrane potential and volume homeostasis of mitochondria. Cell 91: 627-637

7. Prehn JHM, Jordán J, Ghadge GD, Preis E, Galindo MF, Roos RP, Krieglstein J and Miller RJ (1997) $\mathrm{Ca}^{2+}$ and reactive oxygen species in staurosporine-induced neuronal apoptosis. J. Neurochem. 68: 1679-1685

8. Heiskanen KM, Bhat MB, Wang HW, Ma JJ and Nieminen AL (1999) Mitochondrial depolarization accompanies cytochrome $c$ release during apoptosis in PC6 cells. J. Biol. Chem. 274: 5654-5658

9. Finucane DM, Waterhouse NJ, Amarante-Mendes GP, Cotter TG and Green DR (1999) Collapse of the inner mitochondrial transmembrane potential is not required for apoptosis of HL60 cells. Exp. Cell Res. 251: 166-174

10. Budd SL, Tenneti L, Lishnak T and Lipton SA (2000) Mitochondrial and extramitochondrial apoptotic signaling pathways in cerebrocortical neurons. Proc. Natl. Acad. Sci. USA 97: 6161-6166

11. Krohn AJ, Wahlbrink T and Prehn JHM (1999) Mitochondrial depolarization is not required for neuronal apoptosis. J. Neurosci. 19: 7394-7404 
12. Kane DJ, Sarafian TA, Anton R, Hahn H, Gralla EB, Valentine JS, Örd T and Bredesen DE (1993) Bcl-2 inhibition of neural death: decreased generation of reactive oxygen species. Science 262: 1274-1277

13. Sarafian TA, Vartavarian L, Kane DJ, Bredesen DE and Verity MA (1994) Bcl-2 expression decreases methyl mercury-induced free-radical generation and cell killing in a neural cell line. Toxicol. Lett. 74: 149-155

14. Wiedau-Pazos M, Trudell JR, Altenbach C, Kane DJ, Hubbell WL and Bredesen DE (1996) Expression of Bcl-2 inhibits cellular radical generation. Free Radic. Res. 24: 205-212

15. Yang J, Liu X, Bhalla K, Kim CN, Ibrado AM, Cai J, Peng T-I, Jones DP and Wang $X$ (1997) Prevention of apoptosis by bcl-2: release of cytochrome c from mitochondria blocked. Science 275: 1129-1132

16. Srinivasan A, Foster LM, Testa M-P, Örd T, Keane RW, Bredesen DE and Kayalar C (1996) Bcl-2 expression in neural cells blocks activation of ICE/CED-3 family proteases during apoptosis. J. Neurosci. 15: 5654-5660

17. Mah SP, Zhong LT, Liu Y, Roghani A, Edwards RH and Bredesen DE (1993) The protooncogene bcl-2 inhibits apoptosis in PC12 cells. J. Neurochem. 60: 11831186

18. Murphy AN, Bredesen DE, Cortopassi G, Wang E and Fiskum G (1996) Bcl-2 potentiates the maximal calcium uptake capacity of neural cell mitochondria. Proc. Natl. Acad. Sci. USA 93: 9893-9898

19. Ellerby LM, Ellerby HM, Park SM, Holleran AL, Murphy AN, Fiskum G, Kane DJ, Testa MP, Kayalar C and Bredesen DE (1996) Shift of the cellular oxidationreduction potential in neural cells expressing bcl-2. J. Neurochem. 67: 12591267

20. Shimizu S, Eguchi Y, Kamiike W, Funahashi Y, Mignon A, Lacronique V, Matsuda $\mathrm{H}$ and Tsujimoto $\mathrm{Y}$ (1998) Bcl-2 prevents apoptotic mitochondrial dysfunction by regulating proton flux. Proc. Natl. Acad. Sci. USA 95: 1455-1459

21. Ward MW, Rego AC, Frenguelli BG and Nicholls DG (2000) Mitochondrial membrane potential and glutamate excitotoxicity in cultured cerebellar granule cells. J. Neurosci. 20: 7203-7219
22. Rego AC, Ward MW and Nicholls DG (2001) Mitochondria control AMPA/kainate receptor-induced cytoplasmic calcium deregulation in rat cerebellar granule cells. J. Neurosci. 21: 1893-1901

23. Dispersyn G, Nuydens R, Connors R, Borgers M and Geerts H (1999) Bcl-2 protects against FCCP-induced apoptosis and mitochondrial membrane potential depolarization in PC12 cells. Biochim. Biophys. Acta 1428: 357-371

24. Bossy-WetzelE, NewmeyerDD and Green DR (1998) Mitochondrial cytochrome c release in apoptosis occurs upstream of DEVD-specific caspase activation and independently of mitochondrial transmembrane depolarization. EMBO J. 17: $37-49$

25. Shimizu S and Tsujimoto Y (2000) Proapoptotic BH3-only Bcl-2 family members induce cytochrome $c$ release, but not mitochondrial membrane potential loss, and do not directly modulate voltage-dependent anion channel activity. Proc. Natl. Acad. Sci. USA 97: 577-582

26. Rottenberg H and Wu SL (1998) Quantitative assay by flow cytometry of the mitochondrial membrane potential in intact cells. Biochim. Biophys. Acta 1404: $393-404$

27. Pastorino JG, Tafani M, Rothman RJ, Marcineviciute A, Hoek JB and Farber JL (1999) Functional consequences of the sustained or transient activation of the mitochondrial permeability transition pore. J. Biol. Chem. 274: 31734-31739

28. Mellon PL, Windle JJ, Goldsmith PC, Padula CA, Roberts JL and Weiner RI (1990) Immortalization of hypothalamic $\mathrm{GnRH}$ neurons by genetically targeted tumorigenesis. Neuron 5: 1-10

29. Kane DJ, Örd T, Anton R and Bredesen DE (1995) Expression of Bcl-2 inhibits necrotic neural cell death. J. Neurosci. Res. 40: 269-275 